\title{
Juan Rejano en México: Los criterios del crítico literario
}

\author{
Juan Rejano in Mexico: \\ The Criteria of a Literary Critic
}

\author{
Iliana Olmedo Muñoz \\ El Colegio de México
}

\section{RESUMEN}

Este trabajo analiza la columna que Juan Rejano mantuvo durante décadas en el diario $E l$ Nacional como ejemplo de la crítica literaria que los exiliados españoles realizaron en México, un capítulo importante y poco estudiado del diálogo cultural entre intelectuales exiliados y mexicanos. Aunque el registro de la columna es muy amplio, examinar la labor de Rejano como crítico de narrativa mexicana revela sus filiaciones, su idea de tradición y de calidad literaria. Además descubre, desde el caso concreto de Rejano, cómo los exiliados participaron e influyeron en la conformación del medio cultural mexicano.

Palabras Clave: Literatura mexicana; exilio español en México; historiografía literaria; Juan Rejano; Revista Mexicana de Cultura; diálogo cultural.

\section{ABSTRACT}

Making use of the articles published by Juan Rejano in El Nacional, this paper defines Rejano's criteria in order to make known the critical perspective of Spanish exiles about Mexican literature and to insist in the importance of a dialogue between Mexican and Exile intellectuals. Despite the registry of his column is wide, Rejano's critique about Mexican narrative explains his tastes, his ideas of tradition and literary quality. Moreover, the specific case of Rejano demonstrates how Spanish exiles participated and exerted influence in Mexico's cultural space.

Key words: Mexican Literature; Spanish Exile in Mexico; Literary Historiography; Juan Rejano; Revista Mexicana de Cultura; Cultural Dialogue.

El trabajo creador de los intelectuales del exilio español en México ha sido estudiado con incuestionable hondura en las últimas décadas; su actividad como críticos de la literatura, en cambio, ha sido menos apreciada. Analizar la vertiente crítica de su obra revela de manera tangible no solo los criterios que guían la literatura de creación escrita entonces por los exiliados, sino tam- 
bién su influencia en la configuración histórica de la literatura mexicana. Un destacado ejemplo de esta labor crítica lo ofrece el poeta Juan Rejano (19031976), que fue colaborador asiduo del diario mexicano El Nacional y editor durante dos periodos (1949-1956 y 1969-1976) de su suplemento, la Revista Mexicana de Cultura (RMC).

Rejano valoraba el acceso directo a grandes grupos de lectores que la prensa le brindaba y por eso su labor crítica siempre se vinculó con el periodismo. Desde los años anteriores a la guerra, colaboró en revistas y diarios diversos, primero en su natal Córdoba (Aznar, 2000a: 9; Martín, 1980: 671) y luego en Madrid, en Post-Guerra, La Gaceta Literaria (Servén, 2011: 159176) y Nueva España (Aznar, 2000a: 12). Después de la guerra, ya exiliado en México, reanudó su labor en publicaciones editadas por exiliados, como España Peregrina (1940), España Popular (1940-1968), Nuestro Tiempo (1949-1953) o Las Españas (1946-1956), cuatro revistas que, como señala James Valender, «centraron su atención en la problemática nacional, casi con exclusión de todo lo demás» (2000: 145). Rejano también publicó textos en otros impresos literarios, tanto en los promovidos por exiliados, como Romance (1940-1941), Litoral (1944) y Ultramar (1947), como en los dirigidos por mexicanos, Letras de México (1936-1946) y Taller (1938-1941). Colaboró asimismo en Ars (1942-1943), una revista mexicana dedicada a la plástica, donde incluso realizó crítica de música. Sin embargo, donde desarrolló una labor crítica estable y donde se ocupó de temas y autores mexicanos fue en la sección cultural de El Nacional, en una columna que publicaba, esporádicamente, desde su primer artículo (apareció el 11 de octubre de 1942) y con mayor constancia a partir de 1945. Durante un par de meses de 1946 Rejano la llamó «Reloj de arena», pero desde abril de 1950 la tituló «Cuadernillo de señales». En julio de 1954, trasladó la columna del diario al suplemento cultural del mismo periódico, la Revista Mexicana de Cultura, que él mismo dirigía. Desde entonces siguió publicando su columna semanalmente, aun cuando había cambiado la dirección del suplemento; solo eliminó su encabezado en 1969. Entre 1966-1967, Juan Rejano compaginó con el «Cuadernillo de señales» varios artículos que aparecieron en El Nacional firmados con el pseudónimo «Rafael María Lucena» ${ }^{1}$. En esos años Joaquín Fernández de Córdoba se encargaba de la dirección del suplemento —incluso cambió su nombre a Suplemento Cultural. En 1968 Alejandro Carrillo tomó la dirección y dio al suplemento el título de La Cultura Nacional. Cuando Rejano volvió

${ }^{1}$ Manuel Aznar (2000b: 21) y Teresa Hernández (2003: 8) consignan el uso de este pseudónimo. Tanto los temas como el estilo de dichas colaboraciones coinciden con los de Rejano. Sin embargo, a diferencia del propio Rejano, Rafael María Lucena se presenta como mexicano. Por lo mismo, cabe suponer que la creación de este pseudónimo corresponde a una estrategia destinada a concederle a Rejano mayor libertad para expresar en público sus opiniones acerca de México y su literatura. 
a dirigirla en 1969, dejó de emplear el pseudónimo y recuperó el antiguo nombre del suplemento. El último texto que publicó en este diario fue el poema «La montaña y el mar» (1973: 8). Esta constancia demuestra, como señala Blas Sánchez Dueñas, que:

La intensa actividad periodística y hemerográfica de Rejano en México, [lo] erigió en uno de los escritores cardinales en la encrucijada de la literatura del exilio, al pasar por sus manos buena parte de las novedades bibliográficas, hasta convertirse en voz autorizada e influenciadora en el contexto de los cauces creativos de su tiempo (2011: 110).

Los artículos de Rejano aparecidos en El Nacional —sea en la sección cultural diaria o en el suplemento dominical- muestran, en primer término, su idea de la crítica y, en segundo lugar, lo que entendía por literatura de calidad. Ambos criterios lo guían a la hora de valorar la literatura publicada en México. En estos artículos Rejano sostiene el propósito formativo en el que funda su proyecto periodístico. Un propósito que en 1967 describió así:

Estas breves y simples reflexiones, como muchas otras en igual sentido que hemos hecho en este cuadernillo, van encaminadas, no a crear pesimismo ni a sembrar pánico, sino a despertar la conciencia de los que parecen dormidos, de los que por lo visto se han acostumbrado a la cantinela de estos últimos años y ya no ven en ella sino eso: una cantinela (1967: 5).

A partir de esta idea, Rejano comenzó su columna desarrollando dos vertientes que más tarde amplió: por un lado, realizó una exploración de las costumbres y la geografía de México en los textos que llevaban el encabezado «Ciudades y pueblos»; por otro, presentó la tradición lírica española bajo el título de «Páginas del romancero». De manera paralela y conforme avanzaba el tiempo, incluyó reflexiones sobre la situación española y textos acerca de autores particulares, análisis críticos de obras o semblanzas del personaje. En la mayoría hablaba de poetas españoles coetáneos (como Celso Amieva, Pedro Garfias y Emilio Pardos); en menor medida puso atención a varios mexicanos, sobre todo a los entonces jóvenes (como Rubén Bonifaz Nuño, Antonio Mediz Bolio y Mauricio de la Selva). Dedicó pocas columnas a la poesía latinoamericana, aunque no faltaron reflexiones suyas sobre Rubén Darío. También examinó a poetas europeos, como el Conde de Lautréamont, Adam Mickiewicz, de quien publicó una traducción libre², o Heinrich Heine. En segundo lugar comentó la obra y la figura de narradores españoles (Cervantes, Galdós, Herrera Petere), mexicanos (Ermilo Abreu Gómez, Fernando Benítez, Mónico Neck, pseudónimo de Antonio Ancona) y europeos (Julio Fucik,

\footnotetext{
${ }^{2}$ Selección de poemas de Adam Mickiewicz (1855-1955), México, Ediciones Legación de Polonia, 1957. En la portada aparece la leyenda: «Se edita para conmemorar el centenario de la muerte del gran poeta polaco». Las ilustraciones corrieron a cargo de los miembros del Taller de Gráfica Popular.
} 
Heinrich Mann, Jean Paul Sartre). En último término dedicó algunos textos al arte teatral (de dramaturgos como Carlos Arniches, Alejandro Casona y Emilio Carballido). En estos artículos, Rejano discutió a autores cuya propuesta le interesaba o con los que creía tener cierta correspondencia ideológica o estética.

$\mathrm{Su}$ acercamiento a la literatura mexicana es gradual y avanza de manera progresiva conforme se acumulan sus años de residencia; de esta manera, sus artículos dejan de centrarse en el paisaje físico del país para ocuparse cada vez más en los autores. Esto no obsta para que en sus artículos mantenga su preocupación por la situación de España y su literatura.

\section{IDEA DE LA CRÍTICA LITERARIA}

Rejano entiende el periodismo diario como un esfuerzo de información y de difusión. Por tanto, la crítica aparecida en estos medios funciona como guía dentro del medio de la cultura. En su columna semanal, pretende rescatar a autores del pasado, apoyar a los activos y, en menor medida, dar a conocer a algunos de los nuevos. De este modo, la crítica, desde el punto de vista de Rejano, lleva el conocimiento de tal o cual obra al gran público (es una herramienta de divulgación) y, al señalar su valor, consolida y, a largo plazo, canoniza un proyecto creativo. Además de desempeñarse como difusor, el crítico comenta, discrimina y cataloga a autores y obras. Rejano ejerce en el medio cultural mexicano un papel de clasificador y de consejero capaz de señalar las obras que merecen la atención de los lectores. A partir de un examen de su trabajo crítico, esperamos perfilar la postura crítica de Rejano y, más adelante, la que tiene acerca de la narrativa, para evaluar la manera en que su formación ideológica se permea en las lecturas que realiza de los autores mexicanos y cuál es su papel en la configuración de la historia de la novela mexicana.

Rejano apunta que la objetividad no existe en la crítica literaria: le resulta muy claro que, dentro del proceso de canonización de un escritor (en el que participan por igual premios y reconocimientos), intervienen elementos externos a la sola calidad. Rejano cree que en México es muy común que los críticos se apoyen en criterios ajenos a la literatura a la hora de medir el valor de una obra literaria; que el ejercicio crítico que ahí se realiza está plagado de afectos y de desafectos. De hecho, a su juicio: «la política literaria es tan complicada y peligrosa como la política a secas» (1948: 3). Y, como Rejano busca mantenerse al margen de estos lodos, se considera a sí mismo no un crítico sino tan solo un comentarista: "Yo no soy crítico, mis actividades literarias habituales no se encauzan por la crítica, aunque ahora es frecuente que los poetas comenten entre sí las obras y se digan lo que entre poetas deberían callarse» (1950: 4). Sin embargo y puesto que la crítica, con sus silen- 
cios y con sus observaciones, juega un papel sustancial en el conocimiento de un autor, en la difusión de su obra y en la construcción de la historia de la literatura, se ve obligado a ejercerla. Eso, a pesar de saber que la crítica en México es escasa y deficiente: «Es verdad que en nuestros días la crítica literaria ha quedado reducida, en líneas generales, a un mero registro de fichas bibliográficas o, cuando más, a un repique de amistosas - y amigables- campanillas» (Rejano, 1950: 4).

Rejano encuentra en la asignación anual del Nobel un buen ejemplo de la manera en que se articulan los entresijos de la política cultural. A su juicio, el premio Nobel de literatura otorgado a Churchill en 1953 fue una maniobra creada para celebrar la vertiente política del premiado. Churchill era un político honorable, pero un «mediocre escritor» (Rejano, 1953a: 3). El prestigio internacional del ministro británico influyó en el jurado más que la calidad literaria de su obra: «A Churchill, como es bien sabido, se le otorgó no para realzar una obra literaria, que en él era cosa secundaria, sino para reforzar una personalidad eminentemente política en la cual concurrían multitud de rasgos gratos a los círculos del capitalismo» (Lucena, 1967b: 4). A pesar de que cuestiona la validez del Nobel y a pesar también de sus «discrepancias poéticas» (Hernández, 2008: 38) con Juan Ramón Jiménez, en 1956 Rejano aplaude la asignación de este galardón al autor de Platero y yo: «de sobra sé yo que, en torno al Premio Nobel, merodean los intereses políticos como negros moscardones. Pero, aun así, siempre es posible conducirse a la altura, no caer en torpes compromisos políticos demasiado evidentes» (1956b: 6). Años después y con el pseudónimo de «Rafael María Lucena», Rejano afirmó: «Al fin y a la postre, como no pocos ignoran, el Premio Nobel no es solo un premio literario o científico: es también, en el fondo, un premio político» (1967b: 4).

Ahora bien, puesto que el mismo Rejano se apoya en criterios políticos cuando evalúa obras en su columna, no deja de ser contradictoria esta exigencia suya de que, a la hora de juzgar un texto, el crítico no debe confundir las intenciones políticas de un autor con el valor literario de su obra. De hecho, para un crítico como Rejano, se ve que, al contrario, es muy importante especificar la orientación política del autor en cuestión. Es algo que se observa, sobre todo, cuando analiza la obra de los escritores españoles, a quienes valora según su actitud hacia el franquismo. En el campo de la literatura española Rejano optó por apoyar, por un lado, a autores exiliados cuyas obras versaban sobre España, y por otro, a escritores peninsulares que daban testimonio de la situación del país o que (como Victoriano Crémer, a quien elogia en su columna) pretendían formar la conciencia política de los españoles. Desde su enfoque, el ser fiel a la causa de la República española elevaba la calidad moral de los autores de tal modo que, en último término, la importancia de su obra dependía de la fidelidad del autor a cierto tipo de valores. 


\section{LA FORMACIÓN CRÍTICA DE REJANO}

Dos rasgos personales influyen en la idea de calidad defendida por Rejano: su condición de exiliado y su formación literaria, que en términos teóricos sigue ciertos paradigmas ideológicos de los años treinta, sobre todo cuando se trata de evaluar la narrativa. De ahí que el presente trabajo centre su atención únicamente en la visión que tiene Rejano sobre la novela mexicana.

En las primeras décadas del siglo XX, la tecnología condicionó las «nuevas recepciones de los productos culturales, se crearon estéticas nuevas, se popularizó la cultura que adquirió mayor y más rápida distribución» (Salaün, 2005: 253). Por otra parte, se tendió a promover las expresiones populares al mismo tiempo que las expresiones cultas, lo cual dio lugar a la producción simultánea de: una literatura preocupada por el público, de una literatura que buscaba alejarse del público y de una literatura que se movía en una zona intermedia entre estos dos extremos. La literatura acentúa la polarización entre alta y baja cultura; de esta manera, una vertiente del arte moderno «tiende a perder contacto con la vida cotidiana de las personas» (Berman, 1988: 144), mientras que otra, en el intento por acercarse, se tropieza con lo social. Según un estudioso: «Los autores sociales querían comunicarse con sus lectores, a través del reconocimiento de la alteridad» (Fuentes, 1993: 14). Aquí surge la pregunta acerca del destinatario, que es un tema que inquieta a Rejano a lo largo de sus años de exilio. En varios de sus artículos publicados en El Nacional, el poeta discute el sustantivo público, un término que suele emplearse para referirse a un grupo muy diverso de individuos sin fijarse en las diferencias de clase social que pudieran distinguirlos. En lugar de público, Rejano propone el uso del término pueblo, que sí delimita un grupo social identificable como tal: «Se trata de que no seamos rebaño y, sobre todo, abstracción. Abstracción, nunca. Ésa es la peor de las categorías. Pueblo, sí. El pueblo puede ser masa —masa, conjunto o reunión de personas, pero tiene jerarquía social» (1947: 4).

En la década de los años treinta los escritores hallaron en el pueblo tanto fuentes creativas como una causa que defender. La creencia en «la esencia popular» (Crispin, 2002: 20) originó, por un lado, una literatura que se acercaba al pueblo con la intención de absorber sus expresiones artísticas para enriquecer la propia obra y, por otro, el arte social, cuyos temas provenían del pueblo y que aspiraba a encontrar en él su público. En ambos casos se creía que el arte y la acción política debían realizarse como una tarea educativa (Cobb, 1981: 279-288). Y así se hizo en España: mientras unos buscaban educar al pueblo bajo la óptica de las Misiones y la Barraca, otros intentaban acercarse a la colectividad para aprender de ella. Así, dialogar con el público mediante el arte se convirtió en uno de los principales objetivos de algunos artistas, entre ellos, Juan Rejano.

En esos años, varios autores se dejaron influir por una ideología de partido. El mismo Rejano se afilió al Partido Comunista (Sánchez Montero, 1980: 
123). Según explica Manuel Aznar Soler: «Como marxista convicto y confeso, Rejano defendió estéticamente el realismo socialista, pero fue lo suficientemente inteligente como para no convertirlo en dogma [...]» (2000a: 95). Es decir, Rejano siguió las pautas del marxismo, pero con una flexibilidad que le permitía observar desde otros puntos de vista las capacidades comunicativas del arte más allá de su incidencia en el medio social, sobre todo en el caso de la poesía. Cuando habla de la narrativa muy pocas veces se atreve a salir de la ortodoxia. Su vinculación política debe entenderse no como programa sino más bien como certeza personal. Él y otros de sus coetáneos llegaron a la política por la fuerza de los hechos históricos, que terminan arrastrándolos hacia áreas que no les eran naturales. Ellos mismos las veían como ajenas, afirmaba Rejano en una entrevista: «La política es el arte más difícil que existe. Si viviéramos en una sociedad bien organizada, donde cada hombre realizara las tareas que debiera realizar, yo hubiera dedicado mucho menos tiempo a cuestiones políticas» (Hernández de León, 1990: 338). La vinculación partidista también se entendía como un recurso para conseguir el mejoramiento social y Rejano fue un activo militante ${ }^{3}$. Fiel a esta militancia, en el exilio mexicano Rejano no duda en escribir que el pueblo constituye el principal destinatario de la creación: «Lo que el pueblo representa [...] es la piedra de toque para el escritor. Y nunca el escritor llega a serlo más auténticamente que cuando sabe sentirse tornavoz de las ansias del pueblo, expresión apasionada de la conciencia popular» (1955: 7).

Para Rejano la comunicación exigida a toda auténtica obra de arte se cumple en la literatura social, que propone actuar como revulsivo de la conciencia del lector. La vanguardia social de los años treinta tomó del romanticismo dos formas de actuar: con el objetivo de sorprender al gran público (Calinescu, 1991: 49) y con el fin de criticar la sociedad (Plejánov, 1974: 18). Los tomó y los reformuló con la intención de transformar a esa sociedad que antes se limitaba a cuestionar. La propuesta del arte social coincide, en un sentido moral, con la concepción que tiene Rejano de lo humano; pero, en su alcance, también coincide con la idea que Rejano tiene de la literatura, ya que la obra debe influir estéticamente en el público. Cuando Rejano declara que todo escritor de valía escribe para el pueblo, elimina las vacilaciones acerca de la misión efectiva del arte, que se resume, en último término, en comunicar. Ahí radica la verdadera misión del creador:

Día llegará... ¿llegó ya el día? ¿Continuará indefinidamente la polémica? ¿Seguiremos dudando, pensando en para quién escribimos o realizamos nuestras creaciones artísticas? ¿Puede vivir el artista, a estas alturas, divorciado del pueblo? ¿No está el pueblo ya, entrañado en las concepciones del artista? (1946b: 3).

\footnotetext{
${ }^{3}$ En la semblanza que publicó Mundo Obrero tras el fallecimiento del poeta una pluma anónima informó lo siguiente: «Juan Rejano era miembro de nuestro Comité Central y presidía la Delegación del C.E. del P.C.E. en México» (Anónimo, 1976: 6).
} 
En la comunicación, por tanto, reside la principal cualidad de toda auténtica obra de arte. Todo arte social se implica con el espectador, como ocurre, por ejemplo, en la obra del español Antonio Rodríguez Luna, que según Rejano: «es uno de los pintores que poseen más clara y definida conciencia de su arte: de lo que su arte supone como propósito, como responsabilidad, como medio de comunicación entre artista y hombre» (1971: 9).

El criterio de valor que aplica Juan Rejano a la hora de evaluar la narrativa parte directamente de la formación teórica que adquirió durante los años de preguerra. En la España de los años treinta la novela social representó la opción con la que varios narradores pretendían cumplir con las exigencias de una circunstancia cada vez más politizada. Apoyado en esta noción del arte, Rejano establece en el exilio una distinción entre escritores comprometidos y escritores puristas, similar a la que pretendía escindir la literatura durante los años treinta, aunque eran propuestas que tenían varios puntos en común. Por ejemplo, Rejano basa sus teorías literarias en textos como El nuevo romanticismo (1929), en el que José Díaz Fernández sistematizó los parámetros de una vanguardia social que se opusiera a la vanguardia estética promovida por José Ortega y Gasset. De acuerdo con Díaz Fernández la literatura no podía ser autónoma o pura - la pureza, afirmaba, era un ideal inalcanzable. Al contrario, toda obra creativa aspiraba a actuar sobre la sociedad a la que representaba, a través de un arte, no mimético, sino creativo, que transformaba los referentes al mismo tiempo que los registraba. Sin embargo, hay que recordar que José Díaz Fernández definió la metáfora como «una creación popular, un elemento que reside en la boca del pueblo» (1985: 69); con esto intentaba dar un giro nuevo a las ideas formuladas por Ortega, que había sido el principal impulsor del arte deshumanizado y patrocinador de la colección Nova Novorum — conformada por novelas de Francisco Ayala, Antonio Espina, Pedro Salinas, Benjamín Jarnés y Valentín Andrés Álvarez. Rejano comparte el deseo de Díaz Fernández de alcanzar al público, al que identifica con el pueblo, ya que su apuesta siempre pone el acento en el contenido. Rejano discrepa por completo con el fenómeno crítico que apoyó a la llamada novela formalista española al final de la década de los años veinte:

\footnotetext{
Estuvo de moda, hace unos años, despreciar y poner en entredicho el estilo pobre y oscuro de los grandes novelistas. Críticos de las nuevas generaciones, llevados de un afán esteticista — que no era otra cosa en el fondo-, arremetían violentamente contra el discurso «farragoso» de las novelas balzacianas, contra la forma «folletinesca» de Dostoievski, contra la expresión «garbancera» de Galdós, sin tener en cuenta lo injusto - y lo erróneo- de su actitud. ¿Cuántos escritores del lenguaje rico, cuidado, exquisito, dejarán como ellos un mundo palpitante de seres vivos e inolvidables? (1946c: 7).
}

Una mirada a la labor crítica de Rejano hacia el final de los años veinte y principio de los treinta demuestra su preocupación por destacar, por un lado, la capacidad de crítica social de la novela y, por otro, su facultad de dialogar 
con el lector para crear conciencia. Entre los libros que reseña se encuentran Los topos (1930), de Isidoro Acevedo, que pertenece a la corriente obrerista, la rama con mayor aspiración de denuncia; Los aiducs (1926), de Panait Istrati, autor afiliado a la vertiente testimonial, que denunciaba las miserables condiciones de la sociedad, o La caballería roja (1929), de Isaac Babel, que desde el pacifismo relataba los horrores de la guerra. Los comentarios de Rejano acerca de estos libros aparecen en publicaciones como Post-Guerra o Nueva España (Aznar, 2000b: 12), revistas ambas que se consideraban revolucionarias y que promovían una literatura con enfoque político. Rejano también colaboró en la madrileña Cenit, de cuyo catálogo fueron reeditados algunos volúmenes en México ${ }^{4}$, como ejemplos del arte comprometido que autores como Rejano seguían defendiendo como canónico.

Para muchos de los intelectuales del exilio español la llamada deshumanización del arte seguía siendo un grave error; las ideas de Ortega perfilaban un tipo de literatura a la que su deber como exiliados les impedía volver. Como ejemplo, cabe mencionar la conocida opinión expresada por Max Aub en su Discurso de la novela española contemporánea (1945). Porque Aub no dudó en despachar la novela deshumanizada como un fracaso literario y un espejismo al que habían sucumbido los escritores jóvenes en un primer momento: «Lo grave era que los jóvenes eran sinceros; su estilo, su parquedad morosa respondían a su manera de sentir lo artístico; despreciaban — de verdad- el éxito popular y quien lo consiguiera» (1945: 97) .

Rejano parte de estas mismas pautas para desarrollar las ideas que plantea en el exilio, ya como crítico de la narrativa mexicana. Su práctica como crítico literario parte de una concepción esencialmente dual del arte. Dicho concepto se debe a la íntima relación entre forma y contenido que el escritor encuentra en el arte y en el acto creativo. Una obra centrada únicamente en la forma, de acuerdo con el poeta, carece de validez; sin embargo, no ocurre al revés. Muy congruente con la posición que exigían los autores del exilio, Rejano pone el acento en el contenido y no duda al declarar que la palabra desnuda es más efectiva que los giros en el lenguaje, o lo que él llama: «La magia de las palabras, que a la hora de pintar una pasión humana o un conflicto del alma, obstaculiza, a veces, más que facilitar el camino» (1956a: 2). El perfil literario de un autor se encuentra más en el asunto de su obra que en su escritura. La exposición transparente de las ideas se crea a partir de un estilo igualmente diáfano;

${ }^{4}$ En 1947 la editorial Colón, con sede en México, publicó Infancia y mocedades de Adrián Zograffi, novela autobiográfica de Panait Istrati. En la página seis figura una aclaración: «Esta edición es reproducción exacta de la hecha por la Editorial Cenit S.A., de Madrid, España». La traducción del alemán estuvo a cargo de Manuel Pumarega y Enrique Diez Canedo, ambos exiliados en México.

${ }^{5}$ Otra formulación de esta idea se encuentra en el artículo de José Herrera Petere, «La novela en paro forzoso», El Nacional, 17 de noviembre de 1942. Se recoge en una antología (Herrera Petere, 1996: 63-65). 
por tanto, el excesivo cuidado en el lenguaje es un estorbo para la buena literatura, porque los dos componentes conviven de manera natural en la literatura de calidad. A Rejano le importa que la obra comunique un mensaje, alcance al lector, de ahí su apoyo a la sencillez. El estilo actúa en función de la tesis que se quiere explicar. Siendo esto así, según nuestro crítico será en la trama y en los personajes donde se expresa la maestría del escritor: "Lo que importa especialmente es el estilo interior del novelista, no el exterior» (1946c: 7). Por tanto, el canon literario debe construirse a partir de autores que desarrollan el contenido. Los grandes novelistas, según expresa Rejano, serían los que expliquen a la sociedad en que viven. En los artículos publicados en El Nacional, Rejano cita la narrativa rural y autobiográfica de Jean Giono ${ }^{6}$, que escribe textos de carácter costumbrista en los que despliega escenarios y ambientes a partir de largas tramas apoyadas en un estilo sencillo. También cita a Cervantes, Balzac, Dickens, Dostoievski, Galdós, Tolstoi, Zola, Scott, Hugo, Sué, como novelistas cuya obra «ha dejado una nutridísima fauna humana que vive ya independientemente de la voluntad que la creó y del vehículo que la condujo hasta nosotros» (1946c: 7). Rejano admite a los autores que saben contar historias y que al hacerlo muestran su época. Una obra valiosa será, por tanto, aquella en que el hombre se fusione con el artista para así dar expresión a la humanidad. Sería una obra donde los personajes muestren su talante a través del diálogo y donde el diálogo construya la atmósfera que contiene el mensaje que el autor desea transmitir. No sorprende entonces que Rejano desatienda en sus críticas a los autores estilistas. Cuando habla de ellos lo hace para ensalzar su habilidad para desarrollar la trama, los temas, los escenarios y los personajes sin mencionar rasgos de estilo, como en el artículo escrito en homenaje a Gabriel Miró con motivo de su aniversario luctuoso (1953b: 3).

\section{DEFINIR LA LITERATURA EN EL EXILIO}

Fueron tantos los españoles que se exiliaron en 1939, que entre todos ellos se fue creando un fuerte sentido de comunidad. Y es que para ellos el exilio representaba un ámbito donde expresar las preocupaciones comunes relacionadas con el país que habían tenido que abandonar. La formación de estos lazos ayudó a que los exiliados encontraran un público en su propia colectividad. Y de ahí la idea de escribir, en primer lugar, para sí mismos, como hizo Paulino Masip, por ejemplo, al escribir sus Cartas a un emigrado español (1939). De todos modos, la extrañeza que siente el autor exiliado al encontrarse viviendo fuera de su ámbito nacional lo lleva, en último término, a preguntarse para quién escribe. Señala Michael Ugarte: «Para un exiliado el problema del lector es pri-

\footnotetext{
${ }^{6}$ A quien dedica una breve reseña en la revista Ars, «La colección poética Nueva Voz», 1 , enero de 1942, p. 74.
} 
mordial, tanto sociológica como estéticamente. El lector potencial del escritor desterrado es tan amorfo como la propia condición del exilio» (1983: 72). Si sus obras versan sobre puntos específicos de la sociedad española que buscan transformar o denunciar, es natural que estos autores se pregunten, por un lado, cómo alcanzar a los lectores españoles si sus libros son vedados en España y, por otro, cómo lograr que estos temas interesen a los nuevos lectores, a los habitantes de los países que le han dado asilo. Se quiere acceder a un público inaccesible, pero del que se habla. Y esto genera una discusión sobre pertinencias — ¿ se debe escribir sobre España? - y a la vez sobre pertenencias — ¿qué tan comprometido con España soy si abandono sus problemas? Si las intenciones primeras de los autores exiliados se dirigían a la tierra perdida, después de la confrontación con la inaccesibilidad de ese público, la única solución consistía en la ampliación de los puntos de mira. Más que nada porque siempre cabía la posibilidad de tener no uno sino dos públicos.

De ahí surge directamente la atracción de Rejano por especificar el papel del receptor en la obra de arte. Más que una preocupación por si las obras de los exiliados fueran leídas o no, su inquietud tiene que ver que el impacto efectivo de sus obras, de la imposibilidad de llegar al público para el que el autor exiliado escribe y al que quiere concienciar. Desde su exilio político Rejano revalida la idea de que las obras artísticas deben ser efectivas, deben tener impacto social. Y por ello propone que el verdadero objetivo de la literatura consiste en acercarse al pueblo. Ya sea para dialogar con él o para representarlo. Estos valores, que Rejano lleva a cabo en su vida (como fiel antifranquista y como miembro del PC), caracterizan su obra crítica. Así, al comentar la literatura mexicana, Rejano propone un acercamiento al lector, entendido como miembro de un pueblo, del que se aprende y al que se espera educar. Esta conciliación entre pueblo y público nutre el paradigma teórico que en el exilio sustenta las reflexiones literarias de Rejano lo mismo que sus planteamientos críticos; por tanto, son también la vara con la que mide la narrativa mexicana - más que la poesía, que requiere un estudio independiente- durante el mismo periodo. Para comprender el trabajo crítico de Rejano acerca de la literatura mexicana hay que examinar ambas áreas por separado, ya que los criterios de Rejano a la hora de examinar la prosa son muy concretos y constantes a lo largo de su vida; en cambio, su visión de la poesía es más elástica y extensa. Quizá porque él mismo en su obra de creación fue más flexible. Conviene, por tanto, observar sus criterios acerca de la narrativa mexicana como punto de entrada a la definición de su postura crítica.

\section{REJANO Y LA NARRATIVA MEXICANA}

Por creer que una obra de calidad es una obra que pretende llegar al mayor número de lectores, es decir, a los sectores sociales menos educados, 
Rejano apoya a los novelistas mexicanos que guían sus obras hacia una estética que desarrolla en primer lugar un propósito de comunicación. En esta línea, Rejano destaca la naturaleza inmediata y verídica de las narraciones y señala, por ejemplo, el valor testimonial, realista y popular de la novela autobiográfica de José Mancisidor titulada Se llamaba Catalina (1958), que «es también un relato de infancia, una especie de memorias, breves y fragmentadas, de los primeros años, cuyo lugar de acción es el puerto de Veracruz» (1959a: 4). Rejano también encuentra en los cuentos de Fernando Benítez, reunidos en un volumen publicado por la editorial Leyenda, Caballo y dios: relatos sobre la muerte (1945), un ejemplo de calidad literaria, por su capacidad de comunicarse con el pueblo. Otros críticos han señalado esta misma característica en la obra de Benítez. Clara Passafari, por ejemplo, escribe: «la preocupación esencial que guía la producción de Benítez, tanto la periodística como la narrativa, es la convicción de que el escritor es el «abogado del pueblo», el hombre que ayuda a que la gente tenga conciencia de sus problemas» (1968: 189). En fin, para Rejano no hay obra que ilustre mejor sus ideas acerca de la prosa que la de Benítez, con quien colaboró desde el arranque de la RMC. Durante los años 1947-1948 Benítez fue director tanto de El Nacional como de su suplemento, la $R M C$. Tras su salida de ambas publicaciones, el mexicano mantuvo buen trato con Rejano, lo mismo que con el suplemento en cuyas páginas publicó con frecuencia.

A partir de estos objetivos, los elementos en los que Rejano sustenta su criterio para valorar la prosa son: tramas supeditadas al desarrollo de ideas, fidelidad histórica o testimonial, creación verosímil de los personajes y sencillez estilística. La obra de autores mexicanos, siempre según Rejano, tendrá menor o mayor calidad en la medida en que su postura contribuya al mejor entendimiento de la realidad mexicana. De ahí su preferencia por los narradores que siguen una corriente social. De esta manera, Rejano destaca las tres principales vertientes principales de la narrativa social mexicana: en primer lugar, la llamada novela de la Revolución mexicana, como heredera directa del conflicto histórico; en segundo lugar, la narrativa proletaria, que trata asuntos laborales; y, en último término, la novela indigenista, que describe las condiciones de los grupos originarios, históricamente marginados por el sistema político mexicano.

Rejano adapta su idea de la literatura de calidad al nacionalismo promovido por el gobierno mexicano. Así, dirige su atención a los narradores que compartían su planteamiento ideológico y estético, y muy especialmente a tres con los que mantenía lazos de amistad: José Mancisidor (1894-1956), Ermilo Abreu Gómez (1894-1971) y Fernando Benítez (1912-2000). Eran autores que presentaban proyectos de cultura nacional vinculados con el discurso oficial, en la medida en que pretendían lograr una definición de lo mexicano. Pero también eran narradores que cuestionaban la propuesta gubernamental al centrarse en el análisis de las tareas pendientes o irresueltas que el gobierno ha- 
bía dejado tras la Revolución. Rejano ajusta su marxismo al contexto y valora narradores que concuerdan con su concepción de lo literario. Casi siempre analiza de manera favorable las obras que reseña, si bien de repente señala algunos puntos que podrían mejorarse. Por ejemplo, al reflexionar sobre los Ensayos japoneses (1959b) de Manuel Maples Arce —autor que en su momento apoyó a la República española y tenía afinidades ideológicas con Rejano-, concluye que el libro, compuesto por nueve ensayos, da un perfil interesante de la cultura japonesa, pero a veces se pierde en la reflexión y deja más dudas que respuestas acerca de la situación social del Japón en la posguerra (1959b: 4).

Llegado a este punto, hay que señalar el contexto en el cual Rejano se ve obligado a trabajar y desde el cual Rejano realiza sus críticas. Al evaluar la obra de autores mexicanos, la postura política Rejano se topa con la consolidación y estatización de la Revolución mexicana a manos del Partido Nacional Revolucionario (a partir de 1946, Partido Revolucionario Institucional), que sustenta un proyecto cultural nacionalista, basado en dos paradigmas: por un lado, la institucionalización de la Revolución mexicana (el gobierno ahora se considera el legítimo heredero del conflicto) y, por otro, la consagración de la mexicanidad (que el gobierno adopta como categoría que le pertenece y delimita). Claro, no todo en México podía considerarse perfecto: en el sistema político no faltaban pocos aspectos que merecían ser criticados. Pero puesto que muchos de los intelectuales (fuesen mexicanos o españoles exiliados) trabajaban dentro de las instituciones creadas por el gobierno, les quedaba muy poco margen de libertad para criticar.

¿Qué debía hacer un marxista como Rejano frente al dilema de la corrupción del PRI y la necesidad de apoyar la Revolución que le había dado origen? Rejano resuelve esta contradicción eligiendo acatar la disciplina del intelectual exiliado y tomar del PRI y sus instituciones lo que se pudiera rescatar, como sus reformas sociales, sus obras públicas, su apoyo a la cultura. Es decir, Rejano pasa por alto la mayoría de sus defectos; aunque, como se verá más adelante, sí discrepa públicamente con las políticas indígenas del gobierno. Es importante señalar que Rejano fue uno de los pocos poetas exiliados que lograron hacerse de un lugar de importancia dentro del campo cultural mexicano, nada menos que en el diario oficial. Para poder hacerse de este lugar, Rejano tuvo que negociar (en su fuero interno si no es que en los pasillos del poder) con el proyecto de cultura impulsado por el gobierno mexicano e intentar reconciliarlo con sus propias ideas acerca del arte como herramienta de denuncia y como arma de cambio social. De este modo, Rejano opta por realizar críticas menores desde dentro del mismo sistema, sin dejar de destacar, de manera paralela, las acciones positivas surgidas de la Revolución y ejecutadas por el PRI, de ahí su alabanza constante de Lázaro Cárdenas y las muchas reseñas aparecidas en la $R M C$ dedicadas a los libros editados por el gobierno con firmas de sus mismos políticos sobre las medidas positivas conquistadas en materia social y económica. 


\section{a. Novela de la Revolución}

Era evidente que la Revolución había transformado el perfil de México. Rejano creía que algo similar hubiera sucedido en España si la insurrección militar no hubiera puesto fin a la República. En una entrevista declaró que la República fue: «un hecho de muy profunda significación que hubiera podido transformar radicalmente el país en pocos años, de haber contado con un equipo de gobierno que estuviera a su altura» (Hernández de León, 1990: 344). El paralelismo entre la historia política de los dos países fue algo que Rejano quiso llevar a un plano literario, ya que el poeta cordobés creía que el conflicto armado español, al igual que el mexicano, dio como resultado obras literarias de auténtica calidad.

En el México posrevolucionario, al igual que en la España republicana, el enfoque social regía el paradigma de calidad de la novela; si bien a ello se añadía, por supuesto, una preocupación por definir los problemas nacionales: «Specifically in Mexico, one can see that, from the early nineteen-thirties, novels concerned with typically Mexican affairs - the Revolution and its consequences - begin to establish their dominance over cosmopolitan fiction» (Brushwood, 1989: 28). Las novelas innovadoras-cosmopolitas (cuyo más conocido ejemplo son aquellas escritas por el grupo de los Contemporáneos) se siguen publicando, pero son «less prominent in the literary spectrum» (Brushwood, 1989: 29). Acorde con esta perspectiva, Rejano estuvo convencido de que la máxima encarnación de la función social de la literatura se encontraba en la novela de la Revolución, ya que describía el movimiento social que consideraba clave para entender a México.

La creación del concepto «novela de la Revolución» fue una medida tomada por los regímenes posrevolucionarios para fundar una tradición narrativa y validar el proceso histórico. También se consideró una herramienta que apoyaba el discurso nacionalista. De ahí la oposición al término expresada por muchos creadores y críticos. Sin embargo, y como señala una estudiosa: «La reciente creación del sistema posrevolucionario no institucionalizó el canon de la novela de la revolución sino hasta los años sesenta (aunque ya estaba en clara formación desde los años veinte)»(Torres de la Rosa, 2010: 410). Y se fue gestando en las décadas intermedias, con posiciones de apoyo o en contra.

Para Rejano la novela de la Revolución de calidad debía explicar el surgimiento del movimiento armado al exponer las causas que lo generaron. Debía demostrar cómo el conflicto social se convirtió en un conflicto político, es decir, recrear una situación de desigualdad social y un gobierno ciego a los problemas de la gente o, en todo caso, incapaz de resolverlos. La visión de Rejano coincidía, por ejemplo, con la propuesta de José Mancisidor, que apoyó el concepto de «novela de la Revolución» en la década de los años cuarenta y cuya novela, En la rosa de los vientos (1941), pretendía ofrecer una visión de la Revolución distinta a la que habían proyectado novelas como Los de abajo (1915), de Mariano Azuela. 
Los dos militantes del PC, Mancisidor y Rejano, ambos columnistas de $E l$ Nacional, concordaban no solo en su idea de la Revolución y lo que la novela del tema debía mostrar, sino que también compartían una misma idea de la literatura. Cabe señalar que si bien Mancisidor le servía a Rejano de ejemplo de cómo la narrativa social podía recrear el contexto que había dado lugar al enfrentamiento armado, no ocurrió así en el caso de la novela de Azuela, ya que, a juicio de Rejano, en vez de mostrar las situaciones colectivas que la Revolución había venido a transformar, la novela de Azuela se limitaba a representar la violencia de la guerra y a dramatizar la actitud personal asumida por un individuo ante el conflicto social. Rejano no puede valorar positivamente una obra que juzgara tan duramente la Revolución ni que se detuviera en la descripción de sus detalles más escabrosos, puesto que el movimiento social que la Revolución supuso y los cambios que ésta introdujo justifican las fallas y los errores, por demás inevitables en cualquier guerra.

\section{Los de abajo (1915), de Mariano Azuela}

A pesar de que fue muy crítico con la novela, la opinión de Rejano ayudó a afianzar la validez de Los de abajo. Al comentar su reedición en 1963, escribió lo siguiente:

Para mí, Los de abajo, más que una novela propiamente dicha, es una narración viva, apasionada, que se ampara de un realismo violento y, en cierto modo, crítico, de uno de los muchos ángulos de la Revolución mexicana, acaso el menos constructivo, tal vez el más descarnado, pero no por ello desasistido de grandeza (1963: 5).

En el momento en que publicó la reseña, 1963, Rejano mantiene la idea de que el principal objetivo de la prosa consiste en reflejar la realidad del pueblo para, al mostrar sus problemas, acercarse a él. «Toda obra de arte descansa, quiérase o no, en un fundamento social, sobre una base constituida por el pueblo y unas circunstancias históricas, en cuyo conocimiento hay que entrar de lleno alguna vez [...]» (1963: 5). De este realismo encuentra un muy buen modelo en Los de abajo, porque en esta obra «sí supo el ilustre novelista [Azuela] recrear con vigorosos trazos la vida del pueblo, de su pueblo, en un momento de su historia, y de llevar a sus páginas un México auténtico» (1963: 5). Dicho esto, Rejano de todos modos opina que Azuela puso demasiada atención en el conflicto individual del protagonista y dedicó insuficiente esfuerzo al análisis del conflicto colectivo:

Se nota que el autor vio aquellos primeros años de insurrección armada, los años de 1910 a 1915, con los ojos del que aún no distinguía lo que detrás de la inmensa llamarada iba levantándose y, por eso, sentíase seducido, casi exclusivamente, por la anécdota humana, tan profundamente desgarradora a lo largo de aquella conmoción (1963: 5). 
Rejano resaltó que la principal insuficiencia de Los de abajo era que se trataba de una obra que fue crítica con la Revolución y que de hecho cuestionó tanto la calidad intrínseca del movimiento social como los efectos tangibles que el movimiento tuvo en la vida del pueblo mexicano. La falla central de esta novela, de acuerdo con Rejano, reside en su parcialidad, ya que el reflejo literario conseguido por Azuela solo revela una parte del rostro del movimiento social y político de la Revolución mexicana:

Le ocurre a Los de abajo, según mi entender, lo que a «El gesticulador», de Usigli, que, siendo una de las piezas fundamentales del teatro mexicano, nos da una visión parcial de la revolución, precisamente la visión que corresponde a la faceta menos positiva de ella, cuando, sin alterar en lo más mínimo su construcción, hubiera podido ofrecernos también una imagen, siquiera fuese leve, de lo que la revolución tuvo de generoso y grande (1963: 5).

La opinión de Rejano sintoniza con la de los críticos oficialistas que elogiaban aquellas obras que mostraban, y ensalzaban, los logros de la Revolución. La principal característica de Los de abajo y lo que hoy en día más llama la atención de su coordinada y paulatina canonización es precisamente su naturaleza crítica con respecto al movimiento que el gobierno del día quería institucionalizar. De hecho, y como nos recuerda Rafael Olea:

Para poder limar y asimilar la visión negativa de Azuela, los miembros relacionados con los grupos en el poder omitían hablar de la acre censura social presente en su obra. Por ello el discurso oficialista prefería enfatizar la importancia del autor en la definición del carácter mexicano, punto en el que no había ninguna duda (2010: 1).

Rejano, como se observa en el conjunto de su trabajo crítico y en la descripción de los criterios que lo pautan, muestra una actitud ambivalente hacia las ideas oficiales. En el caso de la novela de la Revolución participa en la conformación de la nomenclatura, pero al mismo tiempo cuestiona —en lugar de hacer la vista gorda como la crítica oficial- los aspectos de Los de abajo con los que discrepa, poniendo en entredicho así su supuesta canonicidad.

\section{b. Novela obrera}

El vínculo con el pueblo - campesino, obrero o indígena- es un concepto que está siempre presente en los escritos de Rejano. Por lo mismo es también reivindicado en el elogio que el poeta hace de los prosistas mexicanos que defienden actitudes similares. A dos de estos narradores (Benítez y Mancisidor) dedica poemas en su Libro de los homenajes (1961). En el caso específico de Mancisidor, Rejano vuelve a destacar la preocupación por el pueblo expresada por el narrador de En la rosa de los vientos: 


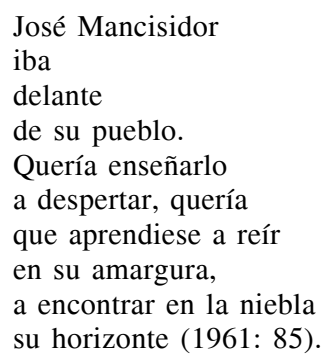

La obra de Mancisidor sigue dos caminos paralelos que conviven también en la narrativa social mexicana de las primeras décadas del siglo XX: la antes mencionada novela testimonial que discute la Revolución y la de tema obrero, de ambiente urbano y que denuncia las condiciones de la clase trabajadora. Al igual que otros narradores sociales, José Mancisidor pretende conquistar al público utilizando las estrategias de la novela tradicional y tiende a valorar más el contenido que la manera de expresarlo. Al buscar un arte que dialogue con la mayoría, da prioridad a una literatura portadora de un mensaje claro y directo. Su intención última consiste en influir en el público a través de historias que ejemplifiquen la injusticia social, económica y política, lo cual lo lleva a evitar el hermetismo, a buscar la sencillez y naturalidad del lenguaje. En palabras de Rejano: «El arte de novelar — de inventar seres y atmósferas novelescos- parece que está reñido con el estilismo, es decir, con el otro arte - también propio del escritor- de hilvanar estéticamente la palabra» (1956a: 2). Al comentar el relato en el que Mancisidor recrea el escenario de su niñez, que también es el del conflicto armado, Se llamaba Catalina (1958), Rejano señala:

El estilo - cosa curiosa_, sin que deje de reflejar lo muy personal de Mancisidor, ofrece resonancias de otros estilos más o menos conocidos y hasta sigue, en algunos pasajes, el ritmo lento y, a la vez, conciso del versículo bíblico con sus repeticiones y regresos. Se diría que, al recordar su infancia, el novelista quiso simplificar los medios de expresión, hasta devolverles la claridad y la ingenuidad que un trance tal le requería (1959a: 4).

La misma facultad narrativa, de estilo claro y sencillo, muestra Macisidor en sus novelas acerca de la explotación del obrero, como La ciudad roja (1932), donde refiere la historia de un grupo sindical veracruzano que fue reprimido con violencia en la década de los veinte (Negrín, 1992: 320). Tanto por su sencillez como por la prioridad que concede al contenido, Rejano considera a la novela obrera ejemplo de calidad narrativa. De igual manera, en 1954, como presidente del jurado del concurso anual de novela de $\mathrm{El} \mathrm{Na}$ cional, Rejano premió Tenemos sed, de Magdalena Mondragón, publicada en 1956, bajo el sello «Ediciones de la Revista Mexicana de Cultura» y como un anexo del mismo diario. Esta novela describe la construcción de la presa 
Falcón en Ciudad Guerrero (Tamaulipas) y muestra los efectos que la tecnología moderna ejerce sobre los habitantes. Más que realizar una crítica a los proyectos del gobierno es un ataque a la tecnología y una exposición de cómo sus avances modifican la vida de las personas comunes. La autora también escribió obras teatrales y textos narrativos que denunciaban la situación de los campesinos, de la mujer y de los indígenas en México (Galván, 1983: 45-81). Es decir, los tres temas que ocupaban a la novela social.

\section{c. Novela indigenista}

Acorde con su propuesta literaria, los otros narradores mexicanos que atraen la atención crítica de Rejano son aquellos que tratan la situación de los indígenas. Al colocarse del lado del pueblo mexicano, Rejano, naturalmente, se suma a la causa indigenista; sin embargo, su actitud hacia la política indigenista del gobierno no es de apoyo incondicional.

Conviene recordar que los exiliados llegan a México en un momento en el que tanto las obras de los muralistas (tan elogiados por Rejano en sus artículos) como los trabajos de los antropólogos, contribuyen a fomentar un movimiento destinado a reivindicar la cultura de los indígenas. Se trata de un movimiento promovido por el gobierno, que así quiere resaltar el pasado indígena prehispánico, al que reivindica como cimiento básico de la identidad nacional. Esto al menos es lo que el propio gobierno anuncia. En realidad, los sucesivos gobiernos de la República se olvidan por completo de las diversas comunidades indígenas que se encuentran entonces en el territorio nacional. Durante años el indigenismo supuestamente era un factor importante en la construcción de la identidad mexicana, ya que el sustrato indígena del país se planteaba como la peculiaridad más positiva de México. Pero cuando se hablaba del indígena, no se pensaba en los seres condenados a vivir en pobreza en los márgenes de la ciudad de México, ni tampoco en las comunidades presentes a lo largo del país, sino en el indígena idealizado, propio de un pasado que se quería lejano y que probablemente nunca existió. Se identificaba al indio con un ser ingenuo, e incluso primitivo, que habitaba su arcadia pueblerina, alejado de la contaminación de la ciudad.

Para resumir, podríamos decir que los sucesivos gobiernos mexicanos incorporaban al indígena en su discurso nacionalista. Sin embargo, la imagen que esperaban crear de México estaba identificada más bien con el mestizo, ya que el mestizo conciliaba las dos vertientes raciales que históricamente estaban en conflicto en México, la hispánica y la indígena. Rejano comulga con esta posición al titular uno de sus libros La esfinge mestiza (1945).Y es que si Max Aub, en su prólogo a la antología de Poesía mexicana (1950-1960), ve «en el mestizaje uno de los mayores logros de la Revolución Mexicana» (Valender, 2005: 273), lo mismo cabe decir de Rejano en su «crónica menor» 
de México. Esta obra, que data de los primeros años de Rejano en el exilio, es una crónica puramente descriptiva, y se lee sobre todo como un homenaje que el escritor rinde al país que le ha dado asilo (Colina, 1982: 422) ${ }^{7}$. No obstante, ya en ella se atisba la principal discrepancia que Rejano desarrolla contra el gobierno posrevolucionario: la hipocresía con que el gobierno presenta la situación socio-económica del indígena.

En La esfinge mestiza Rejano incluye un apartado sobre el «niño indígena», que dedica al escritor yucateco (y gran conocedor de temas mayas) Clemente López Trujillo. Al leer estas páginas, llama la atención en primer lugar el contraste que el autor establece entre la imagen del niño y la del adulto indígena: mientras que el niño tiene la alegría despreocupada de la infancia, al crecer se convierte en un adulto «triste, reconcentrado, huraño» (Rejano, 1945: 277). A partir de ahí, Rejano plantea el drama que la conquista significó para los aztecas y se pregunta si «¿No habrá desde el indito mexicano a sus ancestros un invisible hilo de identificación por donde va y viene el recuerdo de la sangre?»(1945: 278). Rejano sugiere que entre los indígenas existe una memoria de la opresión sufrida y que esta memoria, junto con su marginalidad social (una marginación permitida por el gobierno), explicaría la indefensión en el que viven. De ahí su propuesta de integración a la sociedad: «Para ese drama solo cabe un desenlace: no dejar que el niño crezca y se desarrolle sin haberlo incorporado a la civilización, sin haber despertado en él estímulos y ambiciones legítimos» (Rejano, 1945: 279). Rejano reconoce que el gobierno evade el problema indígena y así fomenta la marginalización de sus comunidades. A su juicio la retórica indigenista de los políticos mexicanos no tiene nada que ver con el trato que efectivamente se les da a los indígenas. Por eso en sus artículos de El Nacional Rejano valora a los narradores —como Ermilo Abreu Gómez, Fernando Benítez, Clemente López Trujillo o Antonio Mediz Bolio- que en verdad centran su atención en los indígenas del México contemporáneo. En su apoyo a estos autores como crítico, Rejano está poniendo el acento en el indígena que el gobierno ignora. Su crítica del gobierno no va mucho más allá de eso. Rejano se encontraba inmerso en un sistema que tenía su propia organización política y fue a partir de sus reglas como debía desarrollar su labor. Es decir, como crítico, se veía obligado a transigir con una cultura pautada por la oficialidad. Además de que la gratitud de Rejano hacia México le imponía muchas restricciones (por no decir nada de aquellas otras que la ley misma marcaba), la $R M C$ era el suplemento cultural del diario oficial del gobierno.

Rejano respaldó y promovió a los autores indigenistas, que ponían en tela de juicio la demagogia oficial, aunque él mismo, como se observa en su tex-

\footnotetext{
${ }^{7}$ Esta opinión es compartida por Rivera-Cordero, que considera que el libro de Rejano es «an attempt to understand a country that seems a mystery and a way to render homage to the land that adopted him»(2006: 310).
} 
to de La esfinge mestiza (1945), no llegó a criticar abiertamente las consignas del gobierno al respecto. Al contrario, de Rejano cabe decir lo que James Valender dijo de Max Aub: «La crítica al régimen, si la hay, se hace de manera suave, insinuándose apenas en ocasionales guiños irónicos» (2005: 272). De hecho, Rejano secundó el nacionalismo literario, bandera que no solo los exiliados (con sus deudas de lealtad) empuñaban: en realidad, la mayor parte de la crítica mexicana buscaba elementos que definieran el carácter nacional en las obras que leían. Explica el estudioso Ignacio Sánchez Prado: «Históricamente, la crítica literaria en México ha estado íntimamente ligada a los intentos mismos de constitución de la literatura nacional» (2009: 4). De este modo, dentro de la definición del ser nacional que pautaba la crítica en México en los años cuarenta, Rejano señaló la mexicanidad de los autores como signo de calidad literaria. Al detenerse en dos relatos del libro Caballo y dios: relatos sobre la muerte (1945), de Fernando Benítez, «Una muerte» y «Otoño», anotó: «En ellos, desde la anécdota al perfil de los tipos y al desenlace de la trama, hallamos un legítimo acento de mexicanidad» (1946a: 3). Es decir, la habilidad de Benítez no solo se limita a los temas, sino a la manera en que los desarrolla, siempre dándoles cierto carácter mexicano. Se trata de una aspiración nacional, ya que, como en el caso de los criterios seguidos a la hora de valorar la literatura española, Rejano busca que la literatura trace el perfil del lugar de nacimiento del autor. Así, propone una literatura universal a través de la narración de lo nacional y da forma a su propuesta al plantear el uso narrativo de temas universales en contextos locales o vistos mediante perspectivas particulares. De ahí su alabanza del libro citado de Benítez, en el que el autor utiliza un tema universal, la muerte, y la resignifica a partir de su tradición y de su experiencia como mexicano:

Lo que ahora consigue Fernando Benítez en su libro tiene mucho que ver con el mundo antiguo de sus ancestros [...] y esta íntima trabazón, que lo hace tan mexicano, revela a la vez lo mucho que de mexicano tienen los mismos relatos, no obstante estar apoyados en una base abstracta, de universal condición, como es la muerte (1946a: 3).

El tratamiento «irónico» (1946a: 3) que Benítez hace de la muerte le parece a Rejano innovador y sorprendente porque «nos la presenta con sus rasgos familiares, con sus acentos cotidianos, terrenal, "humana"» (1946a: 3). Al convertirla en personaje, la acerca al lector. Así, la mayor virtud de Benítez reside precisamente en esta capacidad de familiarizar al hombre «con el momento final» (1946a: 3). De acuerdo con Rejano, el valor de estos relatos (en su mayoría históricos) se halla en su capacidad de reflejar el pasado en confrontación con el presente mexicano a través de una prosa clara: «bella, sencilla y reflexiva» (1946a: 3$)$. 


\section{LA AUTORIDAD CRÍTICA DE JUAN REJANO EN MÉXICO}

Al marcar una pauta de lectura e instituirse como autoridad dentro del medio cultural, Rejano interviene en el desarrollo de la literatura mexicana durante las décadas centrales del siglo XX. Al promover una literatura nacional de intención social, Rejano dio su respaldo a paradigmas literarios que durante los años cuarenta fueron considerados canónicos. Sin embargo, para los tardíos años cincuenta y sesenta una generación nueva pretendía reemplazar estos valores, aunque, como se observa en los artículos publicados en estas fechas por Rejano, el nacionalismo seguía alimentando las discusiones literarias. Desde su llegada a México y hasta los últimos textos suyos publicados en El Nacional, Rejano promueve una narrativa dirigida al pueblo. Los narradores de valía que señala Rejano en la literatura mexicana adoptan una perspectiva social en sus diferentes vetas, todas ellas vigentes en las décadas cuarenta, cincuenta e incluso sesenta, años de la actividad crítica de Rejano, aunque en las dos últimas la propuesta social ya había sido desplazada del eje de prestigio. Conforme avanza el tiempo, no agrega conceptos nuevos a esta postura crítica, pero sí profundiza en la discusión acerca de una literatura universal.

En los años cuarenta, Rejano propone la posibilidad de tratar temas universales a partir de lentes locales, como muestra al destacar el tratamiento literario de la muerte que hace Benítez en su libro de cuentos; en los sesenta, Rejano plantea que la universalidad se logra a partir de una exploración de lo local mexicano, buscando en sus particularidades, como sería, por utilizar el ejemplo anterior, el tema de la muerte. El matiz es muy tenue, casi imperceptible; en realidad podría decirse que el concepto se exacerba, porque va en la dirección contraria, de lo específico a lo general y no de lo general a lo particular. De ahí su conclusión de 1962: «El escritor, cuando lo es auténticamente, encarna y representa la conciencia más alta e insobornable de su país, de sus gentes» (Rejano, 1962: 5).

Hacia finales de los años cincuenta, en distintos suplementos culturales y publicaciones periódicas, pero principalmente en la Revista Mexicana de Literatura, encabezada por Carlos Fuentes y Emmanuel Carballo, la crítica mexicana empezó a cuestionar la validez de los rasgos nacionales como criterios sinónimos de calidad. Anhelando una perspectiva más bien cosmopolita (Cohn, 2002: 98), los críticos empezaron a buscar formas de «contrarrestar la entonces creciente tendencia de la cultura mexicana hacia el nacionalismo» (Pozas, 2008: 54). El entorno crítico empezó a cambiar desde finales de la década de los cuarenta y, a lo largo de los años cincuenta, la visión cosmopolita fue adquiriendo mayor prestigio hasta que en los sesenta, «época que correspondió al debate de la mexicanidad, el campo de producción cultural mexicano fue dominado por un grupo compacto de intelectuales que pretendían legitimar una definición cosmopolita de la literatura mexicana»(Cohn, 2002: 89-90). Sin embargo, la per- 
secución de una literatura nacional seguía siendo la apuesta a la que aspiraban los discursos oficiales. De esta manera, los criterios de Rejano, si bien no concuerdan con las propuestas de los narradores jóvenes, sí caminan en consonancia con los criterios de la ideología oficial. Esto se debe principalmente a Rejano quiere ser congruente con la visión con la que ha comulgado acerca de la narrativa. Rejano nunca favoreció a narradores que se hubieran salido de la esfera de lo local o que hubieran apostado por el cosmopolitismo. De hecho, la línea crítica de la Revista Mexicana de Cultura sigue apoyando el criterio nacional en los años sesenta. El suplemento, por ejemplo, y como señala Jacqueline Covo, era «hostile au nouveau roman latino-amèricaine» (1992: 153). En esas décadas la crítica nueva, lejos de promover una narrativa social-realista basada en la sencillez (tal y como proponía Rejano), pretendía legitimar un paradigma experimental y sobre todo cosmopolita, cuyos representantes empezaban a despuntar en el panorama cultural, como Juan García Ponce, Salvador Elizondo y el mismo Carlos Fuentes. No obstante, Rejano mantiene su propuesta de que la mejor prosa surge desde un entorno local y participa en la construcción de un discurso nacional.

En todos los artículos de Rejano resulta claro el criterio en que se basa para establecer la calidad literaria de los libros que reseña: cuanto más sencillo, directo y accesible el lenguaje y mientras más populares los recursos, mayor será su valor. A través del trazo de sus opiniones literarias, se observa también que su participación en la configuración del canon fue constante, aunque un tanto marginal, ya que en los últimos años empezó a moverse fuera de las directrices que dominaban el campo de producción cultural. En los años sesenta Rejano se deslindó de los nuevos grupos predominantes, al permanecer fiel a las ideas sobre la narrativa en que se había formado y que todavía muchos autores practicaban.

Siendo una de las voces más autorizadas y más activas del medio cultural mexicano, Rejano desempeña un papel importante en la conformación de una narrativa nacional de orientación social. En ese trabajo crítico consiste su principal aportación a la vida cultural del país que le dio asilo: en su capacidad de constituirse como una opción crítica identificada con una propuesta narrativa muy particular basada en el sentido más clásico del realismo. Cuando se topa con otras apuestas narrativas, que no le son caras, se ve obligado a resaltar aspectos acordes a su idea de la novela. Por ejemplo, al reseñar el Premio Rómulo Gallegos, Rejano citó la declaración de Mario Vargas Llosa (ganador en 1967 con La casa verde) de que la literatura era más rica si tenía un sustrato testimonial, sobre todo si partía de «la experiencia personal» (Lucena, 1967a: 4) e inmediata del escritor, aspecto que la crítica soslayó a favor de otros, como la estructura fragmentada, la dislocación temporal y la innovación en el lenguaje. Es decir, al destacar el factor de veracidad y autenticidad del relato, Rejano estaba dando una lectura distinta a la que era la más generalizada de la novela de Vargas Llosa. Su punto de vista convertía 
a la novela en un texto de tintes autobiográficos y le quitaba su carga experimental.

Rejano apoyó la narrativa que pertenecía a una corriente que había perdido centralidad dentro del canon —se alaban las experimentales, intimistas, metaficcionales-, pero que seguía vigente, actuaba dentro del medio cultural y contaba con varios practicantes, muchos de ellos fueron colaboradores de la Revista Mexicana de Cultura, como Héctor Raúl Almanza, Ermilo Abreu Gómez, Andrés Henestrosa o Héctor Pérez Martínez. Más allá de la calidad literaria de estos autores respecto a la de sus contemporáneos, su propuesta debe tenerse en cuenta porque no solo completa el panorama cultural del periodo sino que resulta indispensable para identificar las distintas corrientes - o fuerzas - que interactuaban dentro del medio cultural mexicano. La visión crítica de Rejano autoriza un tipo de narrativa (social) cuya presencia actual en las historias de la literatura es más bien marginal, porque otras corrientes paralelas le restaron protagonismo. No obstante, al conocer las dinámicas culturales que definen el periodo y al escuchar voces como la de Rejano, surge la pregunta acerca del valor real de estos autores y la necesidad de una relectura que trace su perfil con nuevas herramientas. Así, Rejano supo interpretar la literatura de su tiempo y mostró modos distintos de leer, formas que completan el trazo del panorama literario del México de los años cuarenta, cincuenta y sesenta.

\section{FUENTES PRIMARIAS}

[Anónimo] (1976). «Juan Rejano, comunista y poeta», Mundo Obrero. XLVI, 28, p. 6.

Lucena, Rafael María [Juan Rejano] (1967a). «Vargas Llosa y el premio Rómulo Gallegos», RMC. 20 de agosto, p. 4.

Lucena, Rafael María [Juan Rejano] (1967b). «En torno al premio nobel», RMC. 19 de noviembre, p. 4.

Negrín, Edith (1992). «La ciudad roja de José Mancisidor: una novela proletaria mexicana», Actas de la Asociación Internacional de Hispanistas [en línea]. Irvine: USA, pp. 314-322, disponible en: cvc.cervantes.es/literatura/aih/pdf/11/aih_11_5_037.pdf [ref. de 14 de abril de 2015].

Olea Franco, Rafael [2010]. «Una Revolución en la literatura y en la historia», [en línea] [pp. 1-18], disponible en: mexicanistas.eu/uploads/Una_revolucion_en_la_literatura_y_en_la_ historia-Rafael_Olea_Franco.pdf [ref. de 18 marzo 2014].

Rejano, Juan (1946a). «La muerte en siete relatos», El Nacional. 10 de enero, p. 3.

Rejano, Juan (1946b). «Artista y pueblo», El Nacional. 5 de septiembre, p. 3.

Rejano, Juan (1946c). «Polémica literaria. Estilo y creación», El Nacional. 26 de abril, p. 3 y 7.

Rejano, Juan (1947). «Público y pueblo», El Nacional. 14 de enero, p. 3 y 4.

Rejano, Juan (1948). «Las antologías», El Nacional. 8 de enero, p. 5.

Rejano, Juan (1950). «Neruda, los críticos y el silencio», El Nacional. 5 de julio, p. 3.

Rejano, Juan (1953a). «Literatura y política», El Nacional. 18 de octubre, p. 3 y 7.

Rejano, Juan (1953b). «Recuerdo de Gabriel Miró», El Nacional. 6 de diciembre, p. 3 y 7. 
Rejano, Juan (1955). «El escritor ante su pueblo», RMC. 18 de diciembre, p. 7 y 10.

Rejano, Juan (1956a). «Creación y estilo», RMC. 22 de enero, p. 2.

Rejano, Juan (1956b). «Juan Ramón Jiménez y el premio nobel», RMC. 4 de noviembre, p. 6 y 13.

Rejano, Juan (1959a). «Una madre mexicana», RMC. 25 de enero, p. 4.

Rejano, Juan (1959b). «Ensayos japoneses», RMC. 6 de septiembre, p. 4.

Rejano, Juan (1962). «Ermilo», RMC. 24 de junio, p. 5.

Rejano, Juan (1963). «Los de abajo», RMC. 1 de septiembre, p. 5.

Rejano, Juan (1967). «La cantinela», RMC. 10 de diciembre, p. 5.

Rejano, Juan (1973). «La montaña y el mar», RMC. 30 de diciembre, p. 8.

\section{BIBLIOGRAFÍA CITADA}

Aub, Max (1945). Discurso de la novela española contemporánea. México: El Colegio de México.

Aznar Soler, Manuel (2000a). «Ética y estética de Juan Rejano, ensayista exiliado», en Teresa Hernández (ed.), Juan Rejano y el exilio de 1936 en México. Córdoba: Diputación de Córdoba, pp. 92-114.

Aznar Soler, Manuel (2000b). «Estudio introductorio», en Juan Rejano, Artículos y ensayos. Sevilla: Renacimiento.

Berman, Marshall (1988). Todo lo sólido se desvanece en el aire. La experiencia de la Modernidad. Madrid: Siglo XXI.

Brushwood, John (1989). Narrative Innovation and Political Change in Mexico. New York: Peter Lang.

Calinescu, Matei (1991). Cinco caras de la modernidad. Modernismo, vanguardia, decadencia, kitsch, posmodernismo. Madrid: Tecnos.

Cobb, Christopher (1981). La cultura y el pueblo, España 1930-1939. Barcelona: Laia.

Cohn, Deborah (2002). «La construcción de la identidad cultural entre nacionalismo, cosmopolitismo e infraestructura intelectual, 1945-1968», en Kristine Waden Berge y Maarten Van Delden, (ed.), Foro hispánico: revista hispánica de Flandes y Holanda, (El laberinto de la solidaridad. Cultura y política en México (1910-2000). Ámsterdam: Rodopí, pp. 89-103.

Colina, José de la (1982). «México: visión de los transterrados en su literatura», El exilio español en México. México: FCE, pp. 411-425.

Covo, Jacqueline (1992). «Revista Mexicana de Cultura, suplemento cultural de El Nacional (1967-1968)», América. 9-10, pp. 147-154.

Crispin, John (2002). La estética de las generaciones de 1925. España: Pre-textos — Vanderbilt University.

Díaz Fernández, José (1985). El nuevo romanticismo, polémica de arte y literatura. José Manuel López de Abiada (ed.). Madrid: José Esteban editor.

Fuentes, Víctor (1993). «La novela social española 1927-1936: panorámica de un diverso perfil temático y formal», Letras Peninsulares. Spring, pp. 9-27.

Galván Romani, Blanca (1983). Magdalena Mondragón: su vida y su obra. México: Federación Editorial Mexicana.

Hernández, Teresa (2003). «Estudio preliminar» en Juan Rejano, Poesía completa. Córdoba: Diputación de Córdoba.

Hernández, Teresa (2008). «Introducción» en Juan Rejano, La tarde y otros poemas. Madrid: Cátedra.

Hernández de León Portilla, Ascensión (1990). España desde México. México: UNAM.

Herrera Petere, José (1996). Los artículos de El Nacional. Narciso Alba (ed.). Madrid: Ediciones de Torre. 
Martín, Sabas (1980). «Juan Rejano o el verso por rescatar», Cuadernos Hispanoamericanos. 360, pp. 674-681.

Passafari, Clara (1968). Los cambios de la concepción y estructura narrativa mexicana desde 1947. Rosario: Facultad de Filosofía-Universidad Litoral.

Plejánov, Yuri (1974). Arte y vida social. Barcelona: Fontamara.

Pozas Horcasitas, Ricardo (2008). «La Revista Mexicana de Literatura: territorio de la nueva elite intelectual (1955-1965)», Mexican Studies / Estudios Mexicanos. 24, 1, Winter, pp. 53-78.

Rejano, Juan (1945). La esfinge mestiza. Crónica menor de México. México: Editorial, Leyenda.

Rejano, Juan (1961). Libro de los homenajes. México: UNAM.

Rejano, Juan (1971). Antonio Rodríguez Luna. México: UNAM.

Rivero-Cordero, Victoria (2006). «Transatlantic Visions. Imagining Mexico in Juan Rejano's La esfinge mestiza and Luis Buñuel's Los olvidados», Romance Notes. 46, 3, pp. 309318.

Salaün, Serge (2005). «El arte y la máquina. Paradojas de la modernidad escénica (19001939)», en Mechthild Albert (coord.), Vanguardia e intermedialidad: artes escénicas, cine y radio. Madrid - Frankfurt: Vervuert - Iberoamericana, pp. 253-273.

Sánchez Dueñas, Blas (2011). «Magisterio crítico de Teresa Hernández en el poemario crepuscular de Juan Rejano La tarde», Ámbitos. Revista de Estudios de Ciencias Sociales y Humanidades. 26, pp. 109-114.

Sánchez Montero, Simón (1980). «Juan Rejano, dirigente comunista», Litoral: revista de poesía y el pensamiento. 91-93, pp. 123-126.

Sánchez Prado, Ignacio (2009). Naciones intelectuales. Las fundaciones de la modernidad literaria mexicana. USA: Purdue University Press.

Servén Díez, C. (2011). «El joven Juan Rejano y la prensa: La Gaceta Literaria», en María José Porro Herrera y Blas Sánchez Dueñas (ed.), El exilio literario andaluz de 1939. Córdoba: Diputación provincial de Córdoba - Fundación Juan Rejano - Universidad de Córdoba, pp. 159-176.

Torres de la Rosa, Danae (2010). «La nueva novela histórica de la revolución mexicana: ¿apertura del canon o un nuevo ciclo en la narrativa revolucionaria?», en Alicia Rueda, Ignacio Ruiz y Rodolfo Mendoza (ed.), Independencias, revoluciones y revelaciones: doscientos años de literatura mexicana. Xalapa: Universidad Veracruzana, pp. 393-420.

Ugarte, Michael (1983). Literatura española en el exilio. Madrid: Siglo XXI.

Valender, James (2000). «Juan Rejano y la revista Ars», en Teresa Hernández (ed.), Juan Rejano y el exilio de 1936 en México. Córdoba: Diputación de Córdoba, pp. 144-174.

Valender, James (2005). «Max Aub y su antología de Poesía mexicana (1950-1960)», en James Valender y Gabriel Rojo (ed.), Homenaje a Max Aub. México: El Colegio de México, pp. 269-311.

Fecha de recepción: 3 de julio de 2013.

Fecha de aceptación: 5 de febrero de 2014. 
